\title{
Co-Amorphous Combination of Nateglinide-Metformin Hydrochloride for Dissolution Enhancement
}

\author{
Sarika Wairkar ${ }^{1,2}$ (D) and Ram Gaud ${ }^{1}$
}

Received 7 May 2015; accepted 15 July 2015; published online 28 August 2015

\begin{abstract}
The aim of the present work was to prepare a co-amorphous mixture (COAM) of Nateglinide and Metformin hydrochloride to enhance the dissolution rate of poorly soluble Nateglinide. Nateglinide $(120 \mathrm{mg})$ and Metformin hydrochloride $(500 \mathrm{mg})$ COAM, as a dose ratio, were prepared by ball-milling technique. COAMs were characterized for saturation solubility, amorphism and physicochemical interactions (X-ray powder diffraction (XRPD), differential scanning calorimetry (DSC), Fourier transform infrared spectroscopy (FTIR)), SEM, in vitro dissolution, and stability studies. Solubility studies revealed a sevenfold rise in solubility of Nateglinide from 0.061 to $0.423 \mathrm{mg} / \mathrm{ml}$ in dose ratio of COAM. Solid-state characterization of COAM suggested amorphization of Nateglinide after $6 \mathrm{~h}$ of ball milling. XRPD and DSC studies confirmed amorphism in Nateglinide, whereas FTIR elucidated hydrogen interactions (proton exchange between Nateglinide and Metformin hydrochloride). Interestingly, due to low energy of fusion, Nateglinide was completely amorphized and stabilized by Metformin hydrochloride. Consequently, in vitro drug release showed significant increase in dissolution of Nateglinide in COAM, irrespective of dissolution medium. However, little change was observed in the solubility and dissolution profile of Metformin hydrochloride, revealing small change in its crystallinity. Stability data indicated no traces of devitrification in XRPD of stability sample of COAM, and \% drug release remained unaffected at accelerated storage conditions. Amorphism of Nateglinide, proton exchange with Metformin hydrochloride, and stabilization of its amorphous form have been noted in ball-milled COAM of NateglinideMetformin hydrochloride, revealing enhanced dissolution of Nateglinide. Thus, COAM of NateglinideMetformin hydrochloride system is a promising approach for combination therapy in diabetic patients.
\end{abstract}

KEY WORDS: COAM; dose ratio; improved Nateglinide dissolution; Metformin hydrochloride; Nateglinide.

\section{INTRODUCTION}

Drug safety and therapeutic efficacy are critical concerns of the bioavailability of drugs. Thus, poor solubility and subsequently poor oral bioavailability of a drug have become a major challenge in the formulation industry $(1,2)$. The current scenario reveals abundant research carried out on the amorphization of drugs, a state which possesses high thermodynamic energy and significantly improved "apparent" solubility. However, such a structurally disordered metastable form causes free molecular mobility and enhanced chemical reactivity too (3). Therefore, stabilization of the amorphous form is a vital issue as the thermodynamic drive is preordained towards devitrification during the manufacturing process and shelf life of the product $(4,5)$.

In order to stabilize amorphous drugs, solid polymeric dispersions have been widely attempted and extensive

\footnotetext{
${ }^{1}$ Shobhaben Pratapbhai Patel School of Pharmacy \& Technology Management, SVKMs NMIMS, V.L.Mehta Road, Vile Parle (W), Mumbai, Maharashtra 400 056, India.

${ }^{2}$ To whom correspondence should be addressed. (e-mail: sarikawairkar@gmail.com)
}

literature is available on the mechanism of drug-polymer dispersions, molecular interactions therein, and subsequent stabilization (6-8). In some cases, the use of polymers may inhibit the re-crystallization of drugs by increasing glass transition temperature $(\mathrm{Tg})$ as compared to a pure amorphous drug $(9,10)$. It is also assumed that molecular interactions between drug and polymer play an important role in stabilization of the drug. However, amorphous dispersions of drugpolymer are typically hygroscopic, and the absorbed moisture can reduce the $\mathrm{Tg}$ of the dispersion followed by recrystallization of the drug (11). Manufacturing of aforesaid dispersions is critical due to the amount of polymers involved and limited miscibility of drugs into polymers leading to a bulkier dosage form $(12,13)$.

Binary co-amorphous mixture formation has been extensively studied for a decade towards the stabilization of amorphous drugs, which includes the use of small molecules like saccharine, amino acids, citric acid, and sugars (14-16). Firstly, binary amorphous mixtures of two drugs were reported by Yamamura et al. (17) for cimetidine and indomethacin, in which the amorphous precipitates were obtained by solvent evaporation method. Recently, Rade et al. have developed co-amorphous binary mixtures of 
various drugs viz indomethacin-ranitidine hydrochloride (18), in which it has been concluded that both indomethacin and ranitidine hydrochloride were fully converted into the amorphous state through molecular interaction after comilling in contrast to the partially crystalline form of individually milled drugs. In contrast, the simvastatin-glipizide co-amorphous mixture showed improved physical stability without evidence of intermolecular interactions as studied by Lobmann et al. (19). Alleso et al. have illustrated the stabilization of the naproxen-cimetidine amorphous mixtures dictated by molecular-level interactions rather than bulk-level phenomena (20). Therefore, there is a hope and need to rationalize the co-amorphous concept by using a specific clinical dose ratio of pharmacologically relevant drug combinations.

In this present work, an attempt has been made to prepare co-amorphous mixture (COAM) of Nateglinide (NT) and Metformin hydrochloride (MT) in their clinical dose ratio. NT is an oral blood-glucose-lowering agent belonging to the class meglitinides, a class II drug of the Biopharmaceutics Classification System (BCS), having poor solubility of about $0.008 \mathrm{mg} / \mathrm{ml}$ and high permeability (log P, 4.2) $(21,22)$. On the contrary, MT (BCS III) shows solubility in the range of $300 \mathrm{mg} / \mathrm{ml}$ over the entire $\mathrm{pH}$ range of 1-6.8 (23). Several studies have been reported for improving solubility of NT including nanoparticles, solid dispersion, and liquisolid system $(22,24,25)$.

Clinically, combination therapy of oral hypoglycemic agents is reasonable, aiming to minimize side effects with the additional benefit of reduction in the cost of therapy. The combination of NT and MT is rational because it works synergistically in patients whose hyperglycemia is not controlled by monotherapy, and interestingly, its coadministration does not affect the pharmacokinetics of either drug $(26,27)$.

In existing work, mechanically activated (ball-milling) coamorphization of anti-diabetic agents NT and MT has been attempted, aiming at improvement in the dissolution of NT. From the manufacturing viewpoint, ball milling is a green technology and is superior to solvent approaches (28). In this study, NT and MT are ball milled in varying ratios in order to check the feasibility of co-amorphization. Taking into account dosage regimen of both drugs, $120 \mathrm{mg}$ of NT and $500 \mathrm{mg}$ of MT, in same dose ratio, study has been carried out further. The degree of amorphization has been investigated by X-ray powder diffraction (XRPD), differential scanning calorimetry (DSC), Fourier transform infrared spectroscopy (FTIR), and SEM studies. Additionally, physical stability and in vitro dissolution studies have been performed to ensure improved dissolution of NT.

\section{MATERIALS AND METHODS}

\section{Materials}

Nateglinide has been provided as a gift sample by Cipla Ltd., Goa, India, and Metformin hydrochloride was gifted by Sanofi Ltd., Gujrat, India. The chemical structure of both drugs used in the present study is shown in Fig. 1. All other reagents used in the study were of analytical grade.

\section{Methods}

\section{Ball Milling}

Nateglinide and Metformin hydrochloride were milled together to prepare COAM using a ball mill (Scientific Engineering Corporation, India, Model- Secor 141 v.s.) having a stainless steel cylindrical jar. One gram of NT and MT mixture, at 1:1, 1:3, 1:5, and dose ratio (120 mg: $500 \mathrm{mg}$ ), was ball milled using $9 \mathrm{~mm}$ stainless steel balls at ambient temperature with 40 RPM. Trials were taken for optimization of ball-milling time of COAM till $6 \mathrm{~h}$. The crystalline drugs were also ball milled separately for comparison at the same milling parameters. Physical mixtures (PM) were prepared by triturating crystalline NT and MT with a mortar and pestle for $10 \mathrm{~min}$ in similar proportions. All the samples were stored in a desiccator until further use.

\section{Saturation Solubility Studies}

The solubility of NT, MT, and COAM was determined by adding known excess samples to $5 \mathrm{ml}$ of water and a respective buffer (buffer $\mathrm{pH}$ 1.2, $\mathrm{pH} 4.5, \mathrm{pH}$ 6.8, $\mathrm{pH}$ 7.5) separately, and samples were shaken on an orbital shaker for $48 \mathrm{~h}$ at $37^{\circ} \mathrm{C}$ (29). Samples were further centrifuged at 7000 RPM for $10 \mathrm{~min}$, and supernatant was filtered through a $0.45-\mu \mathrm{m}$ membrane filter. Drug content was determined by HPLC (Agilent model-1220 infinity HPLC, with autosampler, a diode array and multiple wavelength detector, and OpenLab software). A Hypersil ODS C18 $(250 \times 4.6 \mathrm{~mm})$, Thermo Fisher Scientific, USA, column was used for the study. For simultaneous analysis of NT and MT, the HPLC method was developed and validated with respect to linearity, accuracy, precision, and robustness at our end. For the HPLC method, the mobile phase consisted of methanol and phosphate buffer $\mathrm{pH} 3.0$ ( $\mathrm{pH}$ adjusted with dilute ortho-phosphoric acid) in the ratio of $75: 25$, with flow rate $0.8 \mathrm{ml} / \mathrm{min}$, injection volume $20 \mu \mathrm{l}$, and detection wavelength $216 \mathrm{~nm}$ being used. The study was performed in triplicate, and results were averaged.

\section{$X$-ray Powder Diffraction (XRPD)}

X-ray powder diffraction studies were performed for samples using an Xpert Pro MPD X-ray Diffractometer (Panalytical, Netherlands) through Xcelerator Detector with diffracted beam monochromator $(k=1.5405 \AA)$. Samples were scanned between 0 and $70^{\circ}(2 \theta)$ using an acceleration voltage and current of $40 \mathrm{kV}$ and $40 \mathrm{~mA}$, respectively. The principle peaks and intensity data were collected and analyzed using the software WINPLOTR (Panalytical, Netherlands). All samples of crystalline and ball-milled NT, MT, and COAM were separately studied by XRPD.

\section{Differential Scanning Calorimetry (DSC)}

Differential scanning calorimetry study was carried out on model DSC 6220 (SII Nanotechnology, SEIKO, Japan). Calibration of the DSC instrument was carried out using indium as reference standard. DSC thermograms were obtained under a nitrogen gas flow of $80 \mathrm{ml} / \mathrm{min}$ at a rate of $10^{\circ} \mathrm{C} / \mathrm{min}$ of all fresh ball-milled mixtures and active pharmaceutical 


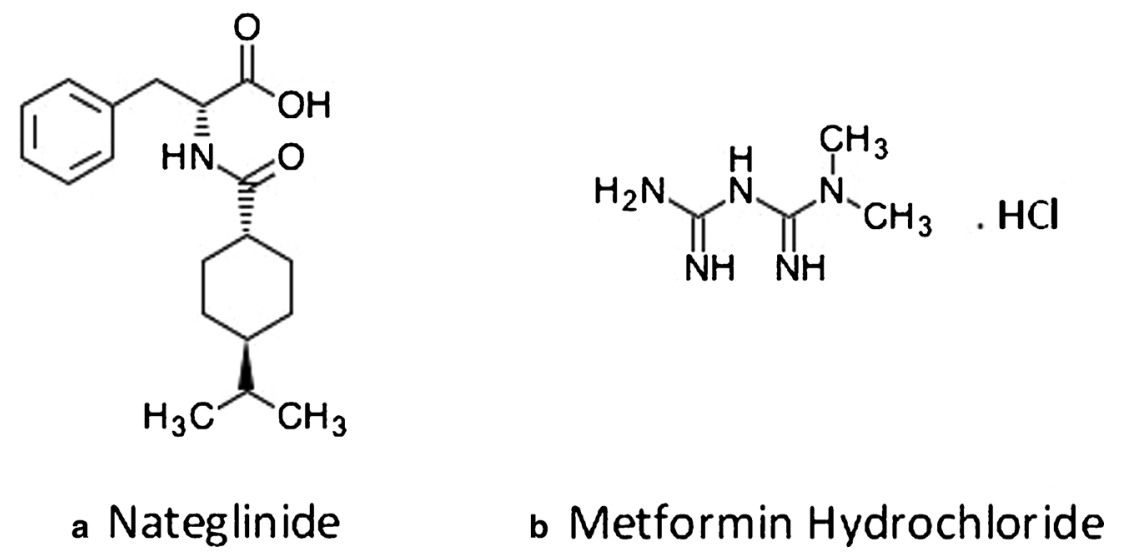

Fig. 1. Molecular structures of $\mathbf{a}$ Nateglinide and $\mathbf{b}$ Metformin hydrochloride

ingredient (API). Approximately 3 to $5 \mathrm{mg}$ of samples was crimped in an aluminum pan and heated at a rate of $10^{\circ} \mathrm{C} / \mathrm{min}$ from 10 to $350^{\circ} \mathrm{C}$. Crystallinity calculation of drugs in the COAM was performed using the following equation given by Rawlinson et al. (30):

$\%$ Crystallinity $=\frac{\Delta \text { HmCOAM }}{\Delta \text { HmDrug } \times W} \times 100$

Where $\Delta$ HmCOAM is the enthalpy of the COAM $(\mathrm{mJ} /$ $\mathrm{mg})$ and $\Delta$ HmDrug is the enthalpy of drug $(\mathrm{mJ} / \mathrm{mg})$ and $W$ is the weight fraction of drug in COAM.

\section{Fourier Transform Infrared Spectroscopy (FTIR)}

FTIR spectra of NT, MT, PM, and ball-milled samples were recorded using an infrared spectrophotometer, modelSpectrum Rx1 (Perkin Elmer, USA) to evaluate possible molecular interactions between the NT and MT. Approximately 2- to 3-mg samples were ground thoroughly with $\mathrm{KBr}$ and mixed uniformly, and the spectra were recorded at a spectral resolution of $\pm 4 \mathrm{~cm}^{-1}$ over a range of $400-4000 \mathrm{~cm}^{-1}$. Triplicate scan of each sample was taken.

\section{Scanning Electron Microscopy}

Scanning electron microscope, ZEISS Ultra FE-SEM (Germany), was used to obtain scanning electron microphotographs of NT, MT, PM, and COAM. An accelerating voltage of $15 \mathrm{kV}$ was used. Before taking a microphotograph, the samples were coated with gold under an argon atmosphere using a sputter coater Emitech K-100× (Quorum Technologies Ltd, UK).

\section{In Vitro Dissolution Studies}

In vitro drug release studies were performed for NT and COAM using USP type I dissolution test apparatus (Electrolab, India) for $1 \mathrm{~h}$ with a speed of $100 \mathrm{RPM}$ and $900 \mathrm{ml}$ of water and $\mathrm{pH} 1.2$ buffer or phosphate buffer $\mathrm{pH} 6.8$ as a dissolution medium (multimedia dissolution study) at $37^{\circ} \mathrm{C}$. One hundred milligrams of samples of the COAM were placed in the basket, and $5 \mathrm{ml}$ aliquots were withdrawn at specific time intervals, and the same amount of volume was replaced with fresh dissolution medium. The samples were analyzed using above described HPLC method. The experiments were conducted in triplicate, and analysis of data was carried out using PCP disso V3 software (Bharati Vidyapeeth, Poona College of Pharmacy, Pune, India).

\section{Stability Studies}

For stability studies, COAM samples were stored in a stability chamber (Thermolab Scientific Equipments Pvt. Ltd., India) at $40^{\circ} \mathrm{C} / 75^{\circ} \mathrm{C}$ condition and ambient temperature for 45 days and were periodically removed at 30 and 45 days and evaluated for physical appearance, XRPD, and in vitro dissolution. Further, COAM samples were characterized for drug content by HPLC analytical method given in the "Saturation Solubility Studies" section.

\section{RESULTS}

\section{Ball Milling and Saturation Solubility Studies}

The experimentally determined solubility of NT, physical mixture, and COAM in purified water have been given in Table I. The $\mathrm{pH}$-solubility profile revealed that NT shows $\mathrm{pH}$-dependant solubility which gradually increases from acidic $\mathrm{pH}$ to alkaline $\mathrm{pH}$ as shown in Fig. 2. Preliminary studies have shown linear rise in the solubility of COAM as the quantity of MT increases in the COAM containing 1:1, 1:3,

Table I. Solubility Study of NT

\begin{tabular}{lc}
\hline Description of API/formulation & Solubility in water $(\mathrm{mg} / \mathrm{ml})$ \\
\hline Crystalline & 0.061 \\
Ball milled & 0.106 \\
NT:MT (1:1 ratio) & 0.346 \\
NT:MT (1:3 ratio) & 0.396 \\
NT:MT (1:5 ratio) & 0.531 \\
NT:MT (Dose ratio) & 0.423 \\
NT:MT physical mixture (dose ratio) & 0.195
\end{tabular}

API active pharmaceutical ingredient, NT Nateglinide, MT Metformin hydrochloride 


\section{$\mathrm{pH}$ solubility profile of NT}

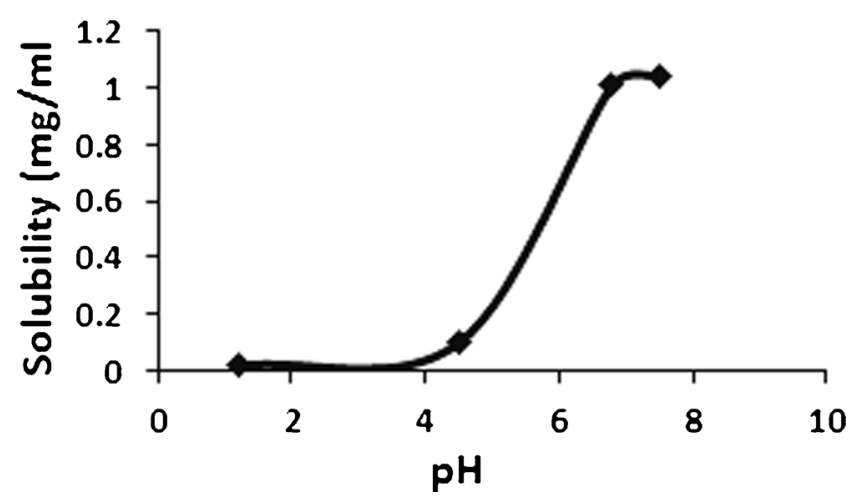

Fig. 2. pH solubility profile of NT

dose ratio, and 1:5. It has been depicted that increase in ballmilling time shows gradual rise in the solubility of NT till $240 \mathrm{~min}$. It is evident from solubility studies that MT possesses free solubility in the overall physiological $\mathrm{pH}$ range, and there is no statistically significant difference observed in the COAM form.

\section{X-ray Powder Diffraction (XRPD)}

Diffractograms of NT shows distinct peaks of crystallinity at $13.5^{\circ}, 16.5^{\circ}, 19.5^{\circ}$, and $24^{\circ}$ and for $\mathrm{MT}$ at $17^{\circ}, 22^{\circ}$, $28^{\circ}, 30^{\circ}$, and $37^{\circ}$ (Fig. 3). The XRPD pattern of COAM showed a reduction in the peak intensity for both drugs within the first $2 \mathrm{~h}$ of ball milling which further decreased after $4 \mathrm{~h}$ of ball milling. When the ball-milling duration was extended up to $6 \mathrm{~h}$, the characteristic peaks of NT completely disappeared for all API ratios, demonstrating conversion to amorphous form; however, low-intensity peaks of MT were seen in COAM. Similarly, when the drugs were separately ball milled for $6 \mathrm{~h}$ under same ballmilling conditions, enhanced amorphism was noted in NT, compared to MT. Relatively, the rate of amorphization of NT was faster than MT in COAM.

\section{Differential Scanning Calorimetry (DSC)}

The DSC thermogram of NT and MT showed endothermic transition peaks corresponding to their melting points at $131^{\circ} \mathrm{C}$ and $235^{\circ} \mathrm{C}$, suggesting the presence of polymorph $\mathrm{B}$ for NT and polymorph A for MT. In PM, NT and MT peaks were seen at their melting points as anticipated. However, the enthalpy of both NT and MT has been reduced from 29.8 to $6.8 \mathrm{~mJ} / \mathrm{mg}$ and 389 to $291 \mathrm{~mJ} / \mathrm{mg}$, respectively, in PM. Interestingly, the melting endotherm for NT has almost disappeared, and the endothermic peak for MT was shifted to 221$225^{\circ} \mathrm{C}$ from $235^{\circ} \mathrm{C}$ in all ratios of COAM. This supports total disappearance of XRPD peaks of NT, as aforesaid. The \% crystallinity data was calculated for NT and MT in COAM sample which shows complete amorphization of NT and $63 \%$ crystallinity of MT in COAM. The thermogram details for aforesaid discussion can be seen in Fig. 4.

\section{Fourier Transform Infrared Spectroscopy}

FTIR spectra of individual drugs and mixtures thereof have been given in Fig. 5. The characteristic bands of NT were observed at the wave numbers of $1209-1384 \mathrm{~cm}^{-1}$ justifying the presence of carboxyl and carboxylate groups. In addition to this peak, C-H stretching between 2867 and $3030 \mathrm{~cm}^{-1}, \mathrm{C}=\mathrm{O}$ vibration at $1742 \mathrm{~cm}^{-1}$, and the $\mathrm{C}-\mathrm{NH}$ bending vibration (amide band II) at $1540 \mathrm{~cm}^{-1}$ were also seen in the NT spectrum. Similarly, characteristic bands of MT were observed including $\mathrm{N}-\mathrm{H}$ stretching (primary and secondary) vibrations at wave number 3371 and $3173 \mathrm{~cm}^{-1}$. Furthermore, N-H deformation vibrations at $1623-$ $1577 \mathrm{~cm}^{-1}$ and $\mathrm{C}-\mathrm{N}$ stretching vibration at $1057-1030 \mathrm{~cm}^{-1}$ were also observed in the MT spectrum. Comparison of FTIR spectra of crystalline NT, MT, and COAM revealed slight broadening of peaks at the $1750-$ to $1700-\mathrm{cm}^{-1}$ region of COAM as compared to pure drugs.

\section{Scanning Electron Microscopy}

Prior to milling, needle-shaped, long, and slender crystals of different sizes were seen in the NT samples, while irregularshape crystals were observed in the MT samples, as seen in Fig. 6. COAM showed small spheres without any traces of needle-shape crystals ensuring the possibility of instantaneous formation of microstructured particles dispersed in the MT matrix, wherein ordered needle geometry has been lost. Microphotograph of PM as raw material showed mixed irregular and needle structures indicating existence of original form of both API.

\section{In- Vitro Dissolution Studies}

Comparison of in vitro dissolution (water media) profiles of crystalline NT, ball-milled NT, physical mixture, and COAM of dose ratio revealed that crystalline and ball-milled API showed very slow drug release rate whereas physically mixed NT and MT resulted in a further improvement in the release rate as seen in Fig. 7. However, it hindered the drug release over $49.65 \%$ at $60 \mathrm{~min}$. COAM of dose ratio exhibited superior dissolution profile in water than the physical mixture and crystalline/ball-milled NT.

Multimedia drug release profiles of crystalline NT, PM, and COAM are illustrated in Fig. 8. Drug release of COAM was significantly higher $(P<0.05)$ in $\mathrm{pH} 1.2$ buffer as compared to crystalline NT or PM. However, there was no major change observed in drug release of $\mathrm{PM}$ and COAM at higher $\mathrm{pH}$ dissolution medium, precisely in phosphate buffer $\mathrm{pH} 6.8$, at the end of $60 \mathrm{~min}$ (Fig. 8). Predictably, Metformin hydrochloride release remained unaffected in multimedia dissolution, and more than $95 \%$ drug release was observed of crystalline API and in COAM form.

\section{Stability Studies}

X-ray powder diffractograms of sample subject to stability studies have shown no characteristic peaks of NT at $40^{\circ} \mathrm{C} /$ $75^{\circ} \mathrm{C}$ for 45 days as seen in Fig. $3(\mathrm{H})$. As partial amorphism was attained for MT initially, low-intensity peaks of MT have been observed in the diffractogram. The in vitro dissolution 


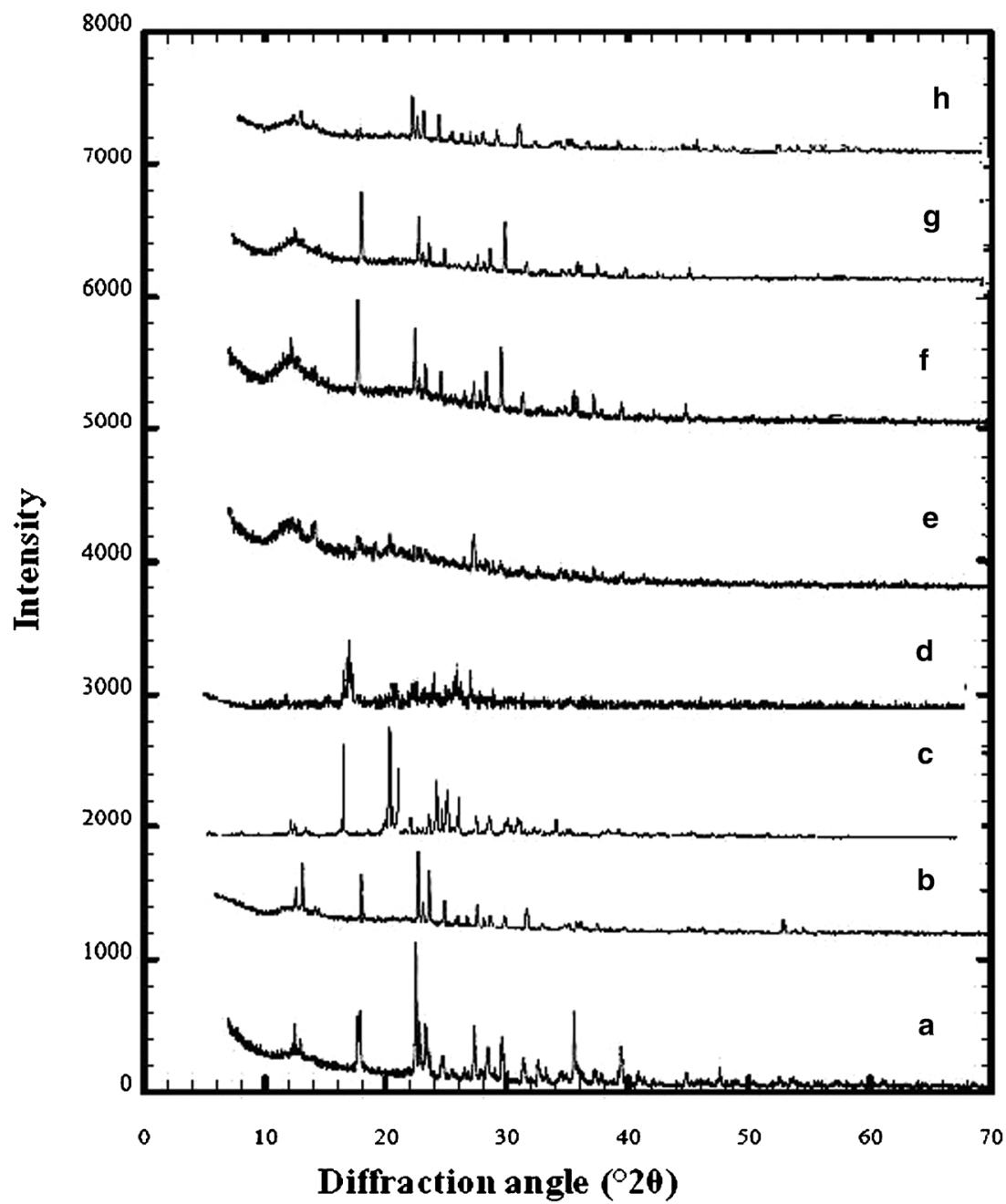

Fig. 3. X-ray powder diffractogram for $a$ crystalline MT, $b$ ball-milled MT, $c$ crystalline NT, $d$ ball-milled NT, $e$ COAM of dose ratio at $6 \mathrm{~h}, f$ COAM of dose ratio at $4 \mathrm{~h}, g$ COAM of dose ratio at $2 \mathrm{~h}$, and $h \mathrm{COAM}$ at $40^{\circ} / 75 \% \mathrm{RH}$ for 45 days

studies also showed satisfactory dissolution profile matching to the initial samples as shown in Fig. 8. Besides, it was also noted that COAM remained as a white to off-white freeflowing powder without changing its physical appearance on stability. Drug content was found in the accepted range of 96.4-98.3\% $w / w$ for NT and 98.2-99.6\% $w / w$ for MT which was similar to the initial values for both API.

\section{DISCUSSION}

In the present study, the combination of NT and MT has been co-processed in dose ratio by ball milling to form a COAM. It has been reported that induction of amorphism by mechanical activation can be related to the milling time and intensity $(18,31)$. Hence, ball-milling time was optimized, and a steady rise in the solubility of NT was observed till $240 \mathrm{~min}$. Thereafter, further lengthening the ball-milling duration does not show any noteworthy change in the solubility of COAM.

The pH-dependant solubility of NT at the physiological $\mathrm{pH}$ range can be attributed to the anionic nature of NT ( $\mathrm{pKa}$ value 3.1). NT exists predominantly in un-ionized form at the acidic $\mathrm{pH}$ of the stomach which causes very low solubility of a drug, whereas higher physiological $\mathrm{pH}$ causes complete ionization of the carboxylic group and improved solubility to a large extent $(32,33)$. Result suggests that each NT molecule may be interacting with more than one MT molecule and thereby increases the solubility of NT with the rise in quantities of MT. Thus, increase in the solubility would result in increased dissolution rate of NT and would resolve the problem of low bioavailability. Being a BCS class III drug, MT shows free solubility in all forms.

Solubility data of COAM is further supported by XRPD studies which reveal a steady decrease in peak intensity of NT with time and after $6 \mathrm{~h}$ complete amorphization of NT has been attained in COAM. This means a decrease in crystallinity of NT leads to improved solubility. On the other hand, partial amorphization of MT was observed which can be contributed to its higher quantity in dose ratio of COAM. Surprisingly, NT alone could not be completely transformed into its amorphous solid form upon ball milling. This can be explained with Nateglinide structural conformation, stabilized 


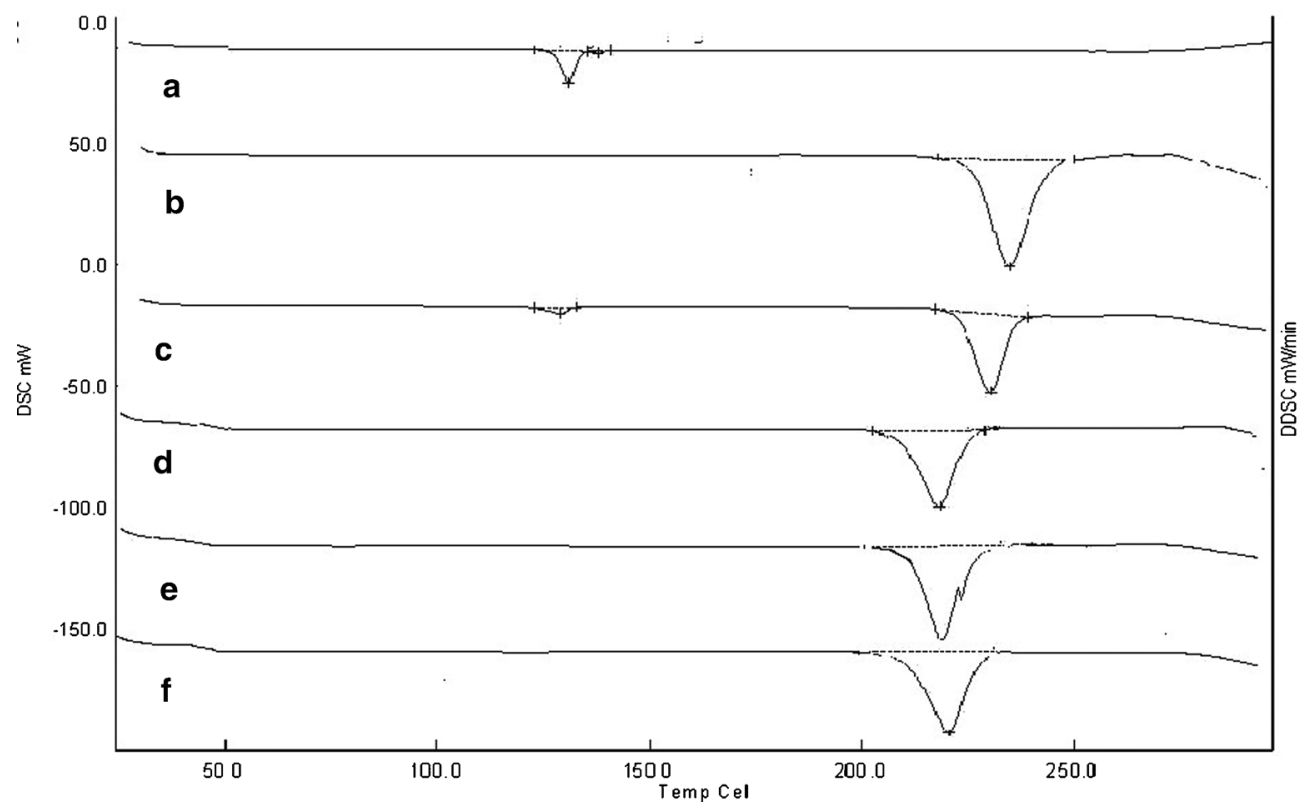

Fig. 4. DSC thermogram of $a$ crystalline NT, $b$ crystalline MT, $c$ physical mixture of NT and MT, $d$ COAM of $1: 1$ ratio, $e$ COAM of $1: 3$ ratio, and $f$ COAM of dose ratio

through intramolecular hydrogen bonds as reported by Bharatam et al. (34). Similar observations have also been reported by Chieng et al. for indomethacin-ranitidine hydrochloride in which individual drugs retained partial crystallinity after co-milling under the same conditions (18).

DSC output had revealed miscibility of NT and MT into COAM in addition to the amorphization shown by XRPD studies. And, a little shift in the melting endotherm with reduction in enthalpy of fusion $221-237 \mathrm{~J} / \mathrm{g}$ has been noted for MT, which is an indicator of molecular-level interaction between NT and MT, which even confirms partial amorphism of MT in COAM. Early amorphization of NT can be attributed to its comparatively small amount of enthalpy, than MT. This observation has also been backed up by \% crystallinity data, which confirms retention of crystallinity of MT in COAM and no evidence of crystalline NT.

For better understanding of interactions between NT and MT, molecular structures of both have been depicted in Fig. 1. NT has two strong proton acceptors and donors each, whereas MT has four proton acceptors and five donors, enabling

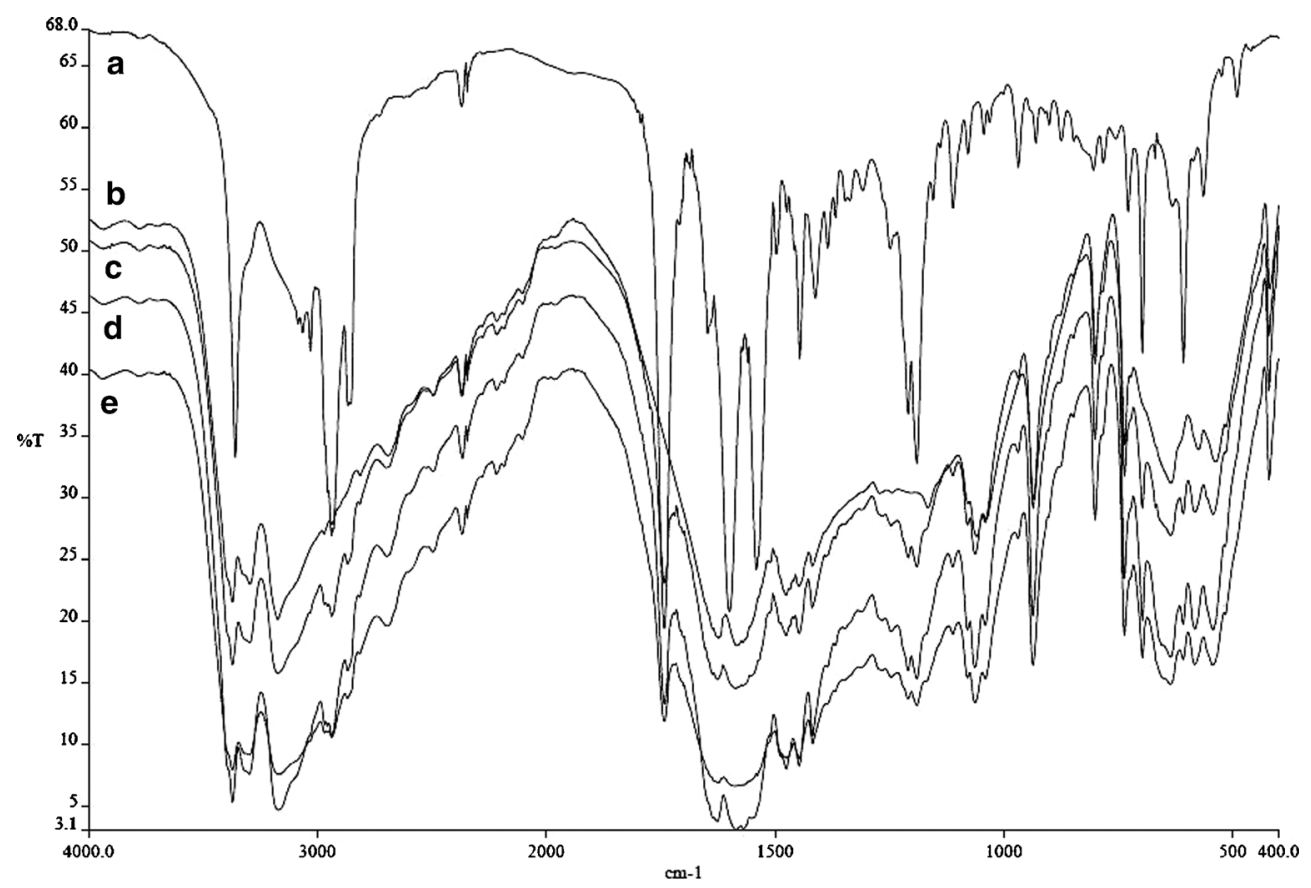

Fig. 5. Fourier transform infrared spectra of $a$ crystalline NT, $b$ crystalline MT, $c$ COAM of $1: 1$ ratio, $d$ $\mathrm{COAM}$ of 1:3 ratio, and $e$ COAM of dose ratio 

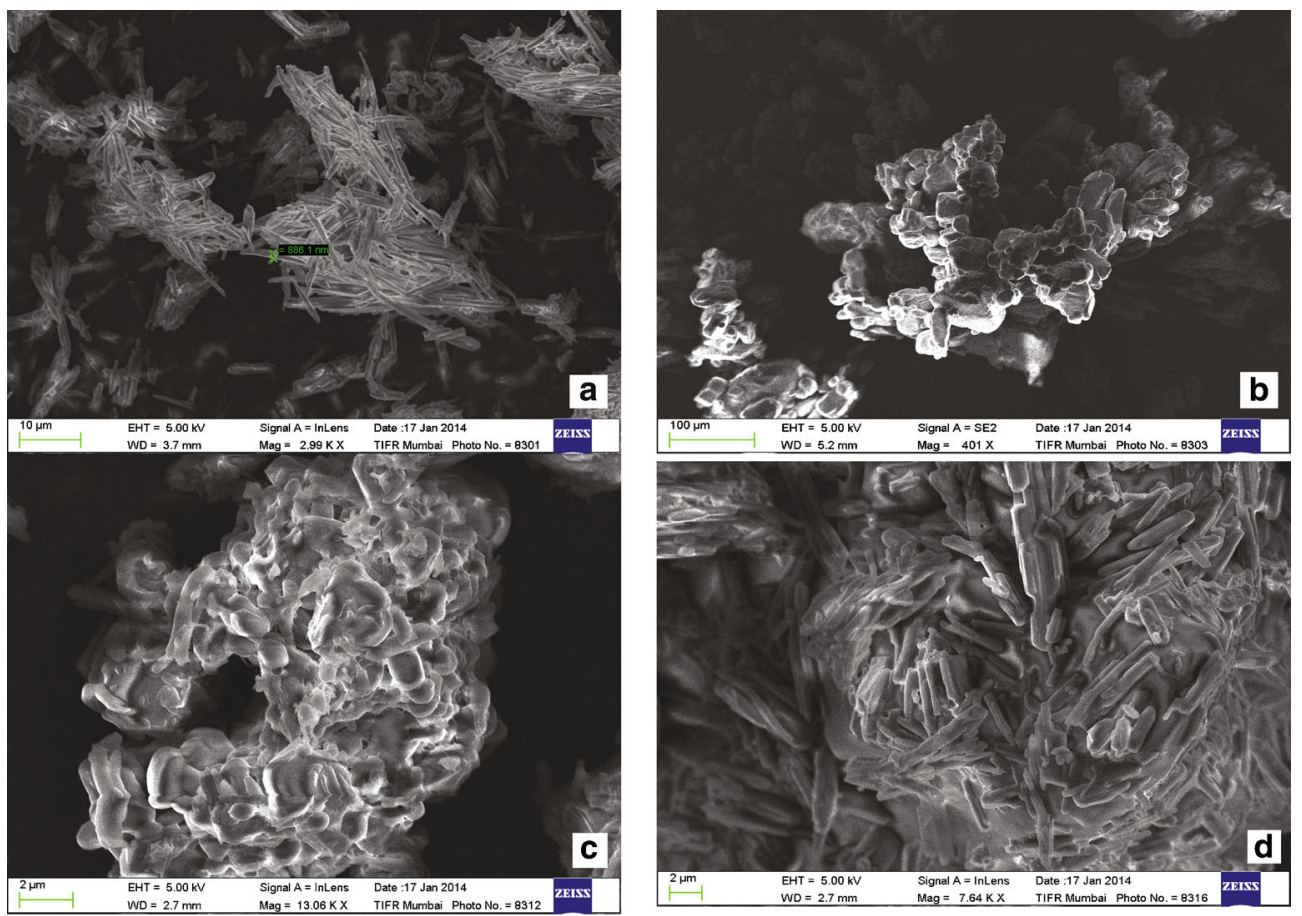

Fig. 6. SEM of a crystalline NT, b crystalline MT $\mathbf{c}$ COAM of dose ratio and $\mathbf{d}$ physical mixture of MT and NT

hydrogen interactions between both drugs. Thus, hydrogen bonding is responsible for molecular interaction between NT and MT which further influences the arrangement of molecules in the COAM $(34,35)$. Generally, band shift and band broadening have been observed in the transformation of crystalline to amorphous compounds (36). Furthermore, specific changes are indicators of hydrogen bonding between both drugs from the vibration regions of the hydrogen-bonded carboxylic acid moiety (1750- to $1700-\mathrm{cm}^{-1}$ region), showing prominent broadening of spectra. Thus, IR spectra confirmed physical interaction between NT and MT, in PM and COAM.
Consequently, SEM microphotographs also support findings of XRPD and DSC data and amorphization of NT. Therefore, it is possible that complete disappearance of crystalline NT due to physical contact with the hydrophilic MT may be responsible for the enhanced drug solubility of the COAM.

Faster drug release rate of COAM in contrast to crystalline NT cannot be explained merely by particlesize changes during the ball-milling process but can be attributed to an amorphous form of drug. As shown by Löbmann et al., binary co-amorphous drug mixtures

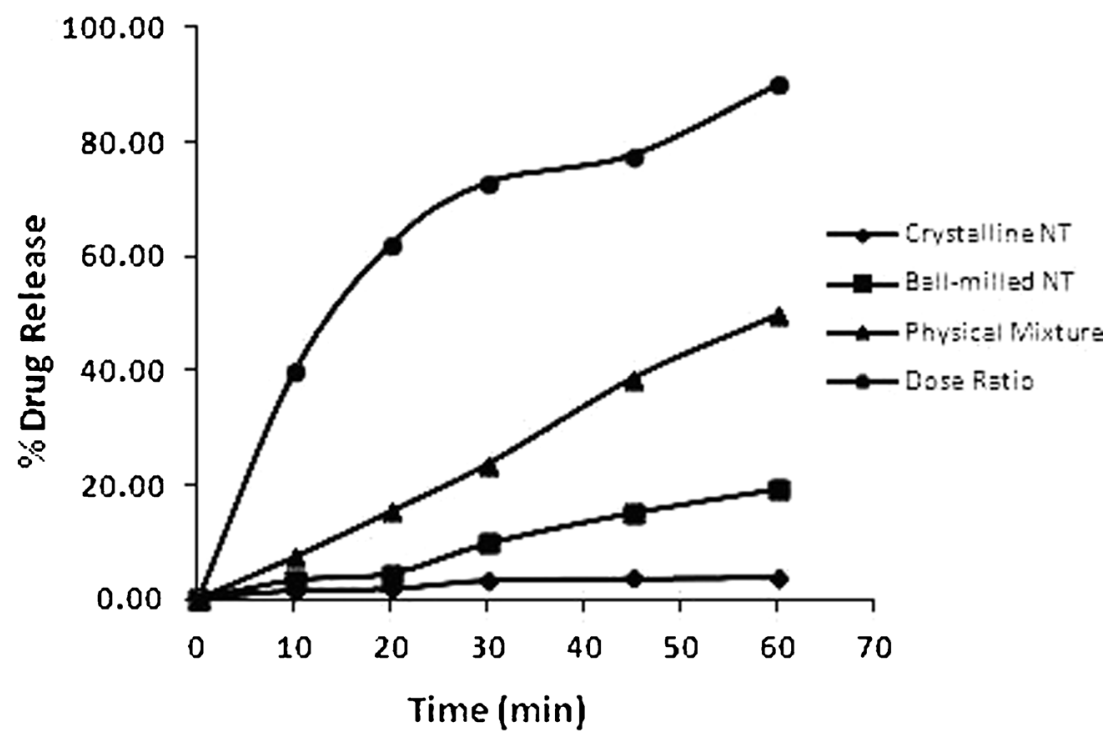

Fig. 7. In vitro dissolution profile of NT 


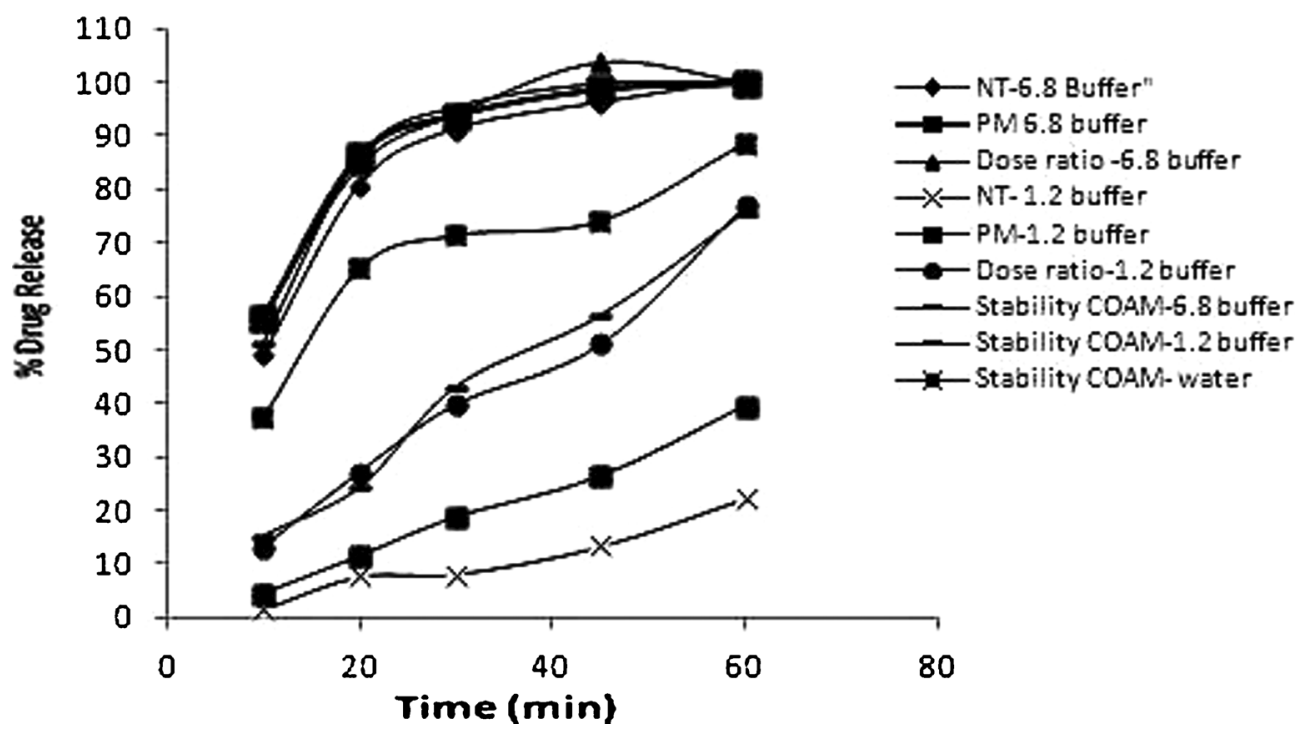

Fig. 8. In vitro multimedia dissolution profiles of NT, PM, and COAM

formed through molecular interactions lead to synchronized, specifically pairwise, dissolution (37). Thus, it can be proposed in effect that the heterodimer of NT-MT is released instead of the individual drug. It has been also hypothesized that the wettability of small lipophilic NT particles was further improved in the presence of highly soluble MT $(38,39)$.

Selection of an appropriate dissolution medium should be based on drug characteristics and formulation features which can clearly discriminate the variations in release profile $(40,41)$. The $\mathrm{pH}$-solubility profile suggested that very low solubility of $\mathrm{NT}$ in the $\mathrm{pH} 1.2$ buffer may lead to the precipitation of NT in the acidic environment of the stomach. Therefore, $\mathrm{pH} 1.2$ buffer has been used as a $\mathrm{pH}-$ simulated medium for dissolution of crystalline NT, PM, and COAM as shown in Fig. 8. Moreover, dissolution parameters should also consider $\mathrm{pH}$ at the site of absorption for the drugs showing $\mathrm{pH}$-dependent solubility (42-44). Higher NT release into the $\mathrm{pH} 1.2$ buffer in COAM form is particularly encouraging because dissolution is going to be a rate-limiting step particularly in the acidic $\mathrm{pH}$ of the stomach for immediate release formulations of NT $(45,46)$. However, there was no major difference observed in the drug release of $\mathrm{PM}$ and COAM at a higher $\mathrm{pH}$ dissolution medium, precisely in phosphate buffer $\mathrm{pH} 6.8$, at the end of $60 \mathrm{~min}$ (Fig. 8). This observation was in line with the higher solubility of NT in alkaline $\mathrm{pH}$. MT has showed almost complete drug release irrespective of dissolution medium. The results were well anticipated and can be credited to its free solubility (47).

Thus, XRPD spectra indicate absence of devitrification for NT in COAM and suggest the stabilization of amorphous NT by MT. Stability samples do not show any difference in in vitro dissolution studies supporting the stabilization of amorphous NT. In addition, physicochemical stability of COAM has been substantiated by the unaffected physical appearance and drug content. Hence, as stated above, the increased stability and enhanced dissolution in COAM can be contributed to molecular interactions between NT and MT $(48,49)$.

\section{CONCLUSION}

Nateglinide and Metformin hydrochloride have been transformed into a co-amorphous state by a simple, green, economic ball-milling process. In co-amorphous form, the non-bonding type of interactions (proton exchange) between NT and MT has significantly increased the drug release rate for Nateglinide in COAM. Hence, the combination therapy of both drugs in the form of COAM appears to be an excellent option for chronic therapy of type 2 diabetes. Thus, the role of co-amorphism can be further investigated for fixed-dose combinations of drugs available clinically.

\section{ACKNOWLEDGMENTS}

Authors are also thankful to Tata Institute of Fundamental Research (TIFR), India, for assistance on XRPD and SEM analysis.

Conflict of Interest The authors declare that they have no competing interests.

\section{REFERENCES}

1. Hoerter D, Dressman JB. Influence of physicochemical properties on dissolution of drugs in the gastrointestinal tract. Adv Drug Delivery Rev. 1997;25:3-14.

2. Lipinski CA, Lombardo F, Dominy BW, Feeney PJ. Experimental and computational approaches to estimate solubility and permeability in drug discovery and development settings. Adv Drug Delivery Rev. 1997;23:3-25.

3. Willart JF, Descamps M. Solid state amorphization of pharmaceuticals. Mol Pharm. 2008;5(6):905-20. doi:10.1021/mp800092t.

4. Yu L. Amorphous pharmaceutical solids: preparation, characterization and stabilization. Adv Drug Deliv Rev. 2001;4:27-42.

5. Ambike AA, Mahadik KR, Paradkar A. Stability study of amorphous valdecoxib. Int J Pharm. 2004;282(1-2):151-62.

6. Noolkar SB, Jadhav NR, Bhende SA, Killedar SG. Solid-state characterization and dissolution properties of Meloxicam- 
Moringa Coagulant-PVP ternary solid dispersions. AAPS Pharm Sci Tech. 2013;14(2):569-77. doi:10.1208/s12249-013-9941-5.

7. Shimpi SL, Chauhan B, Mahadik KR, Paradkar A. Stabilization and improved in vivo performance of amorphous etoricoxib using Gelucire 50/13. Pharm Res. 2005;22(10):1727-34.

8. Sun Y, Zhu L, Wu T, Cai T, Gunn EM, Yu L. Stability of amorphous pharmaceutical solids: crystal growth mechanisms and effect of polymer additives. AAPS J. 2012;14(3):380-8. doi:10.1208/s12248-012-9345-6.

9. Hancock B, Shamblin S, Zografi G. Molecular mobility of amorphous pharmaceutical solids below their glass transition temperatures. Pharm Res. 1995;12(6):799-806.

10. Pokharkar V, Mandpe L, Padamwar M, Ambike A, Mahadik K, Paradkar A. Development, characterization and stabilization of amorphous form of a low Tg drug. Powder Technol. 2006;167:205. doi:10.1016/j.powtec.2006.05.012.

11. Hancock B, Zografi G. The relationship between the glass transition temperature and the water content of amorphous pharmaceutical solids. Pharm Res. 1994;11(4):471-7.

12. Serajuddin AT. Solid dispersion of poorly water-soluble drugs: early promises and recent breakthroughs. J Pharm Sci. 1999;88(10):1058-66.

13. Laitinen R, Löbmann K, Strachan CJ, Grohganz H, Rades T. Emerging trends in the stabilization of amorphous drugs. Int $\mathrm{J}$ Pharm. 2013;453(1):65-79. doi:10.1016/j.ijpharm.2012.04.066.

14. Gao Y, Liao J, Qi X, Zhang J. Coamorphous repaglinide-saccharin with enhanced dissolution. Int J Pharm. 2013;450(1-2):290-5. doi:10.1016/j.ijpharm.2013.04.032.

15. Lobmann K, Grohganz H, Laitinen R, Strachan C, Rades T. Amino acids as co-amorphous stabilizers for poorly water soluble drugs - Part 1: preparation, stability and dissolution enhancement. Eur J Pharm Biopharm. 2013;85(3 Pt B):873-81. doi:10.1016/ j.ejpb.2013.03.014.

16. Masuda T, Yoshihashi Y, Yonemochi E, Fujii K, Uekusa H, Terada $\mathrm{K}$. Cocrystallization and amorphization induced by drug-excipient interaction improves the physical properties of acyclovir. Int $\mathbf{J}$ Pharm. 2012;422:160-9. doi:10.1016/j.ijpharm.2011.10.046.

17. Yamamura S, Gotoh H, Sakamoto Y, Momose Y. Physicochemical properties of amorphous precipitates of cimetidine-indomethacin binary system. Eur J Pharm Biopharm. 2000;49:259-65.

18. Chieng N, Aaltonen J, Saville D, Rades T. Physical characterization and stability of amorphous indomethacin and ranitidine hydrochloride binary systems prepared by mechanical activation. Eur J Pharm Biopharm. 2009;71:47-54. doi:10.1016/j.ejpb.2008.06.022.

19. Lobmann K, Strachan C, Grohqanz H, Rades T, Korhonen O, Laitinen R. Co-amorphous simvastatin and glipizide combinations show improved physical stability without evidence of intermolecular interactions. Eur J Pharm Biopharm. 2012;81:159-69. doi:10.1016/j.ejpb.2012.02.004.

20. Alleso M, Chieng N, Rehder S, Rantanen J, Rades T, Aaltonen J. Enhanced dissolution rate and synchronized release of drugs in binary systems through formulation: amorphous naproxencimetidine mixtures prepared by mechanical activation. J Control Release. 2009;136(1):45-53. doi:10.1016/j.jconrel.2009.01.027.

21. McLeod J. Clinical pharmacokinetics of nateglinide: a rapidlyabsorbed, short-acting insulinotropic agent. Clin Pharmacokinet. 2004;43(2):97-120.

22. Maggi L, Bruni G, Maietta M, Canobbio A, Cardini A, Conte U. I. Technological approaches to improve the dissolution behavior of nateglinide, a lipophilic insoluble drug: nanoparticles and co-mixing. Int J Pharm. 2013;454:562-7. doi:10.1016/j.ijpharm.2013.06.084.

23. Desai D, Wong B, Huang Y, Ye Q, Tang D, Guo H, et al. Surfactant-mediated dissolution of metformin hydrochloride tablets: wetting effects versus ion pairs diffusivity. J Pharm Sci. 2014;103(3):920-6. doi:10.1002/jps.23852.

24. Reddy MKK, Rao BN, Reddy KR. Study on effect of excipients in enhancing the solubility of nateglinide by solid dispersions. Asian J Pharm Tech. 2012;2(1):04-7.

25. Mokale V, Naik J, Patil K, Chaudhari R, Khairnar G. Enhancement of solubility with formulation \& in-vitro evaluation of oral nateglinide compacts by liquisolid technique. Advances Diabetes Metabolism. 2013;1(3):57-64.

26. Hirschberg Y, Karara AH, Pietri AO, McLeod JF. Improved control of mealtime glucose excursions with coadministration of Nateglinide and Metformin. Diabetes Care. 2000;23(3):349-53.

27. Horton ES, Clinkingbeard C, Gatlin M, Foley J, Mallows S, Shen $\mathrm{S}$. Nateglinide alone and in combination with metformin improves glycemic control by reducing mealtime glucose levels in type 2 diabetes. Diabetes Care. 2000;23(11):1660-5.

28. Einfal T, Planinsek O, Hrovat K. Methods of amorphization and investigation of the amorphous state. Acta Pharm. 2013;63:30534. doi:10.2478/acph-2013-0026.

29. The United States Pharmacopoeia and the National Formulary. 37th ed. Unites States Pharmacopoeia Convention; 2014.

30. Rawlinson CF, Williams AC, Timmins P, Grimsey I. Polymermediated disruption of drug crystallinity. Int J Pharm. 2007;336:42-8.

31. Mura P, Cirri M, Faucci MT, Ginès-Dorado JM, Bettinetti GP. Investigation of the effects of grinding and co-grinding on physicochemical properties of glisentide. J Pharm Biomed Anal. 2002;30(2):227-37.

32. Remko M. Theoretical study of molecular structure, pKa, lipophilicity, solubility, absorption, and polar surface area of some hypoglycemic agents. J Mol Struc: Theochem. 2009;897(1-3):73-82.

33. Okamura A, Emoto A, Koyabu N, Ohtani H, Sawada Y. Transport and uptake of nateglinide in Caco-2 cells and its inhibitory effect on human monocarboxylate transporter MCT 1. Br J Pharmacol. 2002;137:391-99.

34. Jain V, Dhaked DK, Kasetti YP, Bharatam V. Computational study on the conformational preferences in nateglinide. J Phys Org Chem. 2012;25(8):649-57. doi:10.1002/poc.1956.

35. Bhende S, Jadhav N. Moringa coagulant as a stabilizer for amorphous solids: part I. AAPS PharmSciTech. 2012;13(2):400-10. doi:10.1208/s12249-012-9755-x.

36. Heinz A, Strachan CJ, Gordon KC, Rades T. Analysis of solidstate transformations of pharmaceutical compounds using vibrational spectroscopy. J Pharm Pharmacol. 2009;61(8):971-88. doi:10.1211/jpp/61.08.0001.

37. Lobmann K, Laitinen R, Grohqanz H, Gordon KC, Rades T. Coamorphous drug systems: enhanced physical stability and dissolution rate of indomethacin and naproxen. Mol Pharm. 2011;8:1919-28. doi:10.1021/mp2002973.

38. Biazar E, Beitollahi A, Rezayat SM, Forati T, Asefnejad A, Rahimi M, et al. Effect of the mechanical activation on size reduction of crystalline acetaminophen drug particles. Int J Nanomedicine. 2009;4:283-7.

39. Zhang F, Aaltonen J, Tian F, Saville DJ, Rades T. Influence of particle size and preparation methods on the physical and chemical stability of amorphous simvastatin. Eur J Pharm Biopharm. 2009;71(1):64-70. doi:10.1016/j.ejpb.2008.07.010.

40. Anand O, Yu LX, Conner DP, Davit BM. Dissolution testing for generic drugs: an FDA perspective. AAPS J. 2011;13(3):328-35. doi:10.1208/s12248-011-9272-y.

41. Tang L, Khan SU, Muhammad NA. Evaluation and selection of bio-relevant dissolution media for a poorly water-soluble new chemical entity. Pharm Dev Technol. 2001;6(4):531-40.

42. Kostewicz ES, Brauns U, Becker R, Dressman JB. Forecasting the oral absorption behavior of poorly soluble weak bases using solubility and dissolution studies in biorelevant media. Pharm Res. 2002;19(3):345-9.

43. Chrzanowski F. Preformulation considerations for controlled release dosage forms: part II-selected candidate support. AAPS PharmSciTech. 2008;9(2):639-45. doi:10.1208/s12249-008-9067-3.

44. Raju V, Murthy KVR. Development and validation of new discriminative dissolution method for Carvedilol tablets. Indian J Pharm Sci. 2011;73(5):527-36. doi:10.4103/0250-474X.99000.

45. Shono Y, Jantratid E, Dressman JB. Precipitation in the small intestine may play a more important role in the in vivo performance of poorly soluble weak bases in the fasted state: case example nelfinavir. Eur J Pharm Biopharm. 2011;79(2):349-56. doi:10.1016/j.ejpb.2011.04.005.

46. Avdeef A. Physicochemical profiling (solubility, permeability and charge state). Curr Top Med Chem. 2001;1(4):277-351.

47. Bretnall AE, Clarke GS. Metformin hydrochloride. In: Florey K, editor. Analytical profiles of drug substance. New York: Academic; 1998. p. 243-91.

48. Karmwar P, Graeser K, Gordon KC, Strachan CJ, Rades T. Investigation of properties and recrystallization behaviour of amorphous indomethacin samples prepared by different methods. Int J Pharm. 2011;417(1-2):94-100. doi:10.1016/j.ijpharm.2010.12.019.

49. Van den Mooter G, Wuyts M, Blaton N, Busson R, Grobet P, Augustijns $\mathrm{P}$, et al. Physical stabilisation of amorphous ketoconazole in solid dispersions with polyvinylpyrrolidone K25. Eur J Pharm Sci. 2001;12(3):261-9. 